\title{
Paying for Drugs After the Medicare Part D Beneficiary Reaches the Catastrophic Limit: Lessons on Cost Sharing from Other US Policy Partnerships Between Government and Commercial Industry
}

\author{
William V. Padula ${ }^{1} \cdot$ Jeromie Ballreich ${ }^{1} \cdot$ Gerard F. Anderson ${ }^{1}$
}

Published online: 30 July 2018

(c) The Author(s) 2018

\begin{abstract}
In 2018, the Medicare Part D catastrophic threshold is $\$ 5000$ in out-of-pocket total drug spending incurred by the beneficiary. Above this, Medicare pays $80 \%$, prescription drug plans (PDPs) pay $15 \%$, and beneficiaries pay a $5 \%$ copay. However, recent growth in catastrophic spending is caused by expensive specialty drugs. The 5\% copay, on top of out-of-pocket spending, could result in beneficiaries not accessing specialty drugs. To assist beneficiaries, the Medicare Payment Advisory Commission (MedPAC) proposes to eliminate beneficiary catastrophic cost sharing, while PDPs pay $80 \%$ and Medicare pays $20 \%$. Our objective was to assess other government cost-sharing approaches and consider how they would affect pharmaceutical access, PDP Part D incentives, and pharmaceutical innovation. We reviewed published literature and government reports on cost sharing between US government divisions or between government and private commercial entities. We discussed their cost-sharing applicability to Part D. We found that the US government has utilized numerous cost-sharing approaches to enhance public-private partnerships. We reviewed four cost-sharing arrangements and their applicability to Medicare: the Byrd-Bond Amendment to the Clean Air Act-Medicare bulk purchases drugs costing $\$ 8000+$; North Atlantic Treaty Organization (NATO) — cost sharing based on high-risk markets; the Ryan White Ryan White Comprehensive AIDS Resources Emergency (CARE) Act—grants to PDPs in high-risk markets and grants to beneficiaries who cannot afford drugs; and the Department of Veterans Affairs - drug price negotiation for expensive drugs. In conclusion, a variety of federal cost-sharing approaches provide precedent for altering PDP cost sharing. The government tends to prefer options that have been tried elsewhere.
\end{abstract}

William V. Padula

wpadula@jhu.edu

1 Department of Health Policy and Management, Johns Hopkins Bloomberg School of Public Health, $624 \mathrm{~N}$ Broadway Ave, Baltimore, MD 21202, USA

\section{Key Points for Decision Makers}

Cost sharing under Medicare Part D protects Medicare beneficiaries with multiple chronic conditions above the catastrophic threshold ( $\$ 5000$ out-of-pocket) by distributing total drug costs between Medicare (80\%), prescription drug plans $(15 \%)$ and beneficiaries $(5 \%)$.

Current out-of-pocket copays make high-cost specialty drugs inaccessible to many beneficiaries, so the Medicare Payment Advisory Commission (MedPAC) recommends eliminating beneficiary copay and redistributing catastrophic cost sharing between prescription drug plans $(80 \%)$ and Medicare (20\%).

Several cost-sharing programs between federal agencies and private entities provide precedent for altering catastrophic cost sharing to reduce beneficiary burden, preserve Part D accessibility and lower drug prices. 


\section{Introduction}

The 2003 Medicare Modernization Act greatly improved access to pharmaceuticals for Medicare beneficiaries by subsidizing access to Part $\mathrm{D}$ prescription drug plans (PDPs) and Medicare Advantage Prescription Drug Plans, both of which are operated by private insurers [1]. PDPs receive risk-adjusted direct subsidies from Medicare based on health status for Part D enrollees and reinsurance payments for high-cost enrollees [2]. Under reinsurance, Medicare Part D shares $80 \%$ of the cost of drugs patients take, and PDPs contribute 15\% for "catastrophic" highcost patients, which is later subsidized by Part D. However, the amount paid by Medicare Part D in reinsurance has increased $7 \%$ since 2017, and 25\% since 2007 [2]. This growth is caused primarily by an increase in the number of beneficiaries reaching the catastrophic level, and places pressure on Medicare to think differently about how to control spending and insulate the patient from soaring drug prices. Furthermore, this cost-sharing arrangement is unusual in that it has three entities: the beneficiary, the PDP, and Medicare.

In addition, the level of cost-sharing changes depending on the amount the beneficiary spends on drugs. In 2018, the beneficiary pays the initial $\$ 405$ deductible under a standard Medicare plan. After the deductible is reached, the beneficiary pays $25 \%$ coinsurance of the amount between $\$ 405$ and $\$ 3750$, and a typical PDP pays $75 \%$. Medicare pays nothing aside from the payment subsidy to the PDP for coverage, while the beneficiary is in the "doughnut hole". After the total drug costs exceed \$3750, the beneficiary pays either 40 or $51 \%$ of the cost depending on whether the drug is branded or generic, while the PDP pays either 10 or $49 \%$, depending on whether it is a branded or generic drug. The pharmaceutical manufacturer pays $50 \%$ in the doughnut hole for branded drugs. Once a beneficiary spends $\$ 5000$ out-of-pocket, between the beneficiary and PDP, the beneficiary enters the catastrophic phase in which the beneficiary pays 5\%, the PDP plan pays $15 \%$, and the Medicare program pays $80 \%$ [3]. This article focuses on prescription drug spending in this catastrophic phase and whether the proportions assigned to each stakeholder (i.e., the beneficiary, the PDP, and Medicare) appropriately incentivize proper management of catastrophic spending between PDPs and Medicare Part D. It is important to remember under these circumstances that the beneficiary has already paid $\$ 5000$ out-of-pocket before they enter the catastrophic phase.

The involvement of three parties in a cost-sharing arrangement for catastrophic coverage creates unique complications given the sparse guidance in the literature. In healthcare, cost sharing rarely extends beyond the insurer and the beneficiary, whereby the insurer designs benefits to manage patient utilization and align manufacturers to price drugs in relationship to demand. In fact, there is actually a fourth entity involved in the cost sharing - the manufacturer. While cost sharing does not actively include the manufacturer in the catastrophic phase, the manufacturer participates in the "doughnut hole". In addition, the manufacturer negotiates with the PDP over the price that is paid in the catastrophic phase. This makes the arrangements much more complicated than the traditional literature on cost sharing and requires a new approach to examine options for improvement.

The cost-sharing provision of the catastrophic phase was designed to provide economic incentives for appropriate drug use by both beneficiaries and PDPs, while at the same time providing financial protection to both beneficiaries and PDPs. Initially, the main concern was beneficiaries with multiple chronic conditions; they are historically likely to be higher utilizers of prescription drugs and would therefore be more likely to have difficulties finding a Part D plan willing to enroll them. Medicare beneficiaries with five or more chronic conditions fill an average of 50 prescriptions per year [4]. This rationale changed when the predominant reason for entering the catastrophic phase became a single expensive drug. Now, instead of making multiple decisions about which drugs to use, beneficiaries are making a choice about a single expensive drug. However, the 12-month timelimited nature of the doughnut hole may not be the best opportunity to observe plan incentives for specialty drugs, and most of the literature on beneficiary cost sharing does not address the implications of making a single high-cost purchase.

The idea that a single expensive drug would cause the beneficiary to immediately enter the catastrophic phase was a minor consideration when the Medicare Modernization Act was passed in 2003 because few drugs were that expensive. However, given the recent growth of "specialty drugs", which Medicare defines as drugs whose price exceeds $\$ 670$ per month, the rationale for cost sharing changed [5]. In 2003 , specialty drugs only accounted for $11 \%$ of total drug spending. By 2014, specialty drug spending accounted for $43 \%$ of total spending among commercial claims; [6] more importantly, specialty drugs accounted for nearly $89 \%$ of expenditures at the catastrophic level [7]. Medicare spending on catastrophic coverage in Part D has increased from $\$ 6.0$ billion in 2006 to $\$ 34.3$ billion in 2015 , representing a $472 \%$ increase compared to just a $106 \%$ increase for overall Part D expenditures (i.e., from $\$ 44.3$ to $\$ 91.7$ billion) [8]. During this period, the number of beneficiaries entering the catastrophic level of spending also increased.

Hepatitis $C$ provides an important example of how specialty drugs influence the drug spend of the beneficiary and Medicare Part D in the catastrophic phase. In 2014, 
Medicare spent nearly $\$ 4.6$ billion on two specialty drugs that treat hepatitis $\mathrm{C}$; the 12 -week course of treatment for these drugs can exceed $\$ 75,000$ [9]. Once the price of the drug exceeds a beneficiary's catastrophic coverage threshold, the Medicare program pays $80 \%$ of the cost of the drug, without any ability to influence the price. The Kaiser Family Foundation has estimated the cost sharing paid by Medicare beneficiaries for certain specialty drugs, including hepatitis $\mathrm{C}$ drugs, and found that costs range from slightly less than $\$ 5000$ to over $\$ 11,000$ [10]. This out-of pocket spending represents a significant percentage of most beneficiaries' social security benefit, placing undue financial pressure on low-income retirees or, more likely, restricting their access to these specialty drugs completely. Medicare beneficiaries, although they may pay \$5000-\$11,000 for these drugs, do not have the ability to negotiate the price. Medicare Part D pays $80 \%$ of the cost of these specialty drugs, but Medicare is not involved in the determination of the price. The PDPs that pay $15 \%$ of the price are the only entities given the responsibility to negotiate the price. Cost sharing is most effective when the entity affected by the cost sharing has an ability to affect the price without completely limiting access.

Specialty drugs in Medicare Part D highlight several concerns about placing patients at financial risk. First, PDPs have only a minority stake in negotiating drug prices in the catastrophic phase, and beneficiaries are having difficulty accessing these specialty drugs because of the high cost sharing. Second, it is unknown whether PDPs would in fact be able to negotiate lower drug prices if they were given the incentive of paying more of the cost sharing. Third, it is unclear how the PDPs would respond if they were responsible for $80 \%$ of the cost in the catastrophic phase. Would they place additional constraints on access to these drugs? There is little evidence that the cost sharing in the "doughnut hole" is reducing prices.

Congress, the Centers for Medicare and Medicaid Services (CMS), and the Medicare Payment Advisory Commission (MedPAC) have recognized the growth of spending for catastrophic coverage with the increased use of highpriced specialty drugs [11]. However, few policy options have been developed to address the growing spending in the catastrophic portion of Medicare Part D. The next section will describe the current MedPAC proposal, discuss various cost-sharing approaches that other federal government agencies have used with private entities, and select several options that could be used to explore catastrophic cost-sharing revisions. Given the lack of academic literature in healthcare on a three-way level of cost sharing, it is appropriate to explore other government programs that have addressed similar issues with public and private entities. Congress often looks for how other government programs have dealt with similar issues.

\section{MedPAC Proposal}

MedPAC is an independent federal body that advises US Congress on Medicare payment issues. In June of 2016, MedPAC examined Medicare Part D spending and highlighted the need to address the impact of high cost drugs on Part D and the need to reform catastrophic Part D coverage. MedPAC proposed that the Medicare percentage drop from 80 to $20 \%$; the beneficiary's cost share, which is currently $5 \%$, be eliminated; and the PDP's percentage increase from the current 15 to $80 \%$ [12]. In 2018, MedPAC has recommended that in order to offset the PDP's much greater financial burden, Medicare would increase the direct subsidy paid to PDPs by $74.5 \%$. This would initially result in a deficit to PDPs; however, plan sponsors would receive additional capitated subsidies rather than reinsurance to offset the remainder of the $80 \%$ copayment [13]. A concern with this proposal is that the beneficiary with multiple chronic conditions or a costly disease such as hepatitis $\mathrm{C}$ might have difficulty getting access to appropriate drugs if the PDP has to pay $80 \%$ of the cost and is concerned about being reimbursed through Part D. While this concern would typically have positioned Medicare to recalibrate risk-adjustment subsidies to maintain PDPs in high-cost markets, this type of risk selection could otherwise be avoided since most beneficiary costs are now easily predictable in the market of pharmaceutical spending for single high-cost conditions [1].

What is most unusual about the MedPAC proposal is that Medicare is usually the majority stakeholder or primary reinsurer. If PDPs became majority stakeholders in a Medicare program, they could use various techniques to avoid enrolling beneficiaries who require specialty drugs or who suffer from multiple comorbid conditions. Moreover, PDPs may withdraw from markets with higher than average rates of high-cost conditions such as hepatitis C, which could impact access to the six protected classes in Part D-immunosuppressants, antidepressants, antipsychotics, anticonvulsants, antiretrovirals, and antineoplastics. Another area of concern is that PDPs may manipulate their formulary to increase complexity across formularies in terms of coverage, pre-authorization requirements, and multiple tiers of drugs, as flexibility of formulary tool use is a key component of the MedPAC recommendations.

\section{History of Cost-Sharing Agreements Between Government and Private Entities}

Most of the empirical research on cost sharing examines the allocation of cost between insurers and patient and investigates how the patient responds to different 
cost-sharing arrangements. Currently, data are lacking on how PDPs might respond to different cost-sharing arrangements. For example, if the cost sharing for PDPs was increased, would some PDPs avoid markets with higher concentrations of patients who reached the catastrophic threshold, or would they have a greater incentive to lower specialty drug prices for Medicare beneficiaries through the power of negotiation? To answer these questions, we sought to examine the cost-sharing arrangements among government entities and between government and commercial entities. We were also interested in how the various government agencies have determined a fair price because this has important implications for innovation by pharmaceutical firms.

The federal government routinely uses cost-sharing arrangements with commercial entities as a mechanism to offset risk to taxpayers and enhance public-private partnerships. It is necessary to pay a rate that encourages private companies to participate in the activity. These cost-sharing models vary in their operation and the proportion of cost sharing between government and commercial entities. The arrangements vary across multiple federal agencies including agriculture, defense, environment, and energy. Table 1 shows some of the cost-sharing arrangements that could provide ideas related to prescription drug coverage. While not all of these cost-sharing arrangements could prove fruitful to Part D, they offer some sense of the volume of cost-sharing agreements that the US government undertakes.

In general, when the government shares the risk, the government takes on an equal or majority share of the risk. These findings make MedPAC's proposal of an 80/20 distribution in favor of Medicare quite unusual unless the upfront risk to PDPs is offset by Part D subsidies. It would be more typical if Medicare were to remain the $80 \%$ stakeholder and reimburse the PDP for a smaller share.

We carefully examine the various government programs and determined that four models that could help policy makers revise Medicare catastrophic coverage are (1) the ByrdBond Amendment to the Clean Air Act; (2) the North American Treaty Alliance (NATO); (3) the Center for Medicare and Medicaid Innovation (CMMI) equal-sided risk models; and (4) the Ryan White Comprehensive AIDS Resources Emergency (CARE) Act. The Department of Veterans Affairs (VA) also provides an example of price negotiation that could be compatible with MedPAC's proposed cost-sharing model. While none of the models offer a perfect analogy to cost sharing in Medicare Part D catastrophic coverage, they do provide a framework that has the potential to be successfully implemented.

The Byrd-Bond Amendment is an example that goes beyond merely just shifting the cost-sharing rates and prescribes a "market-based" policy approach [14]. The NATO model provides a framework for revising Medicare Part D, because the cost-sharing mechanism is similar to the sliding premiums for Medicare Part D. An equal-sided risk model could incentivize PDPs to enter high-risk markets and be rewarded for their willingness to cover expensive patient drug regimens. The Ryan White CARE Act provides a framework that involves three entities and targets high-cost medications.

The fact that these options have been adopted in other governmental programs reduces the risk of significant unintended consequences. These models offer precedent for the US government to follow with respect to rewarding early adopters of untested principles. A summary of these arrangements and their applicability to catastrophic drug coverage is summarized in Table 2.

\subsection{North American Treaty Alliance (NATO)}

NATO's 28 members each contribute to a general fund based on an agreed upon cost-sharing formula equal to about $2 \%$ of gross national income [28]. As a result, the small, less affluent countries receive the benefit of military protection without paying an equal share or equal per capita share. With respect to design for Medicare Part D, there are two aspects of this program that could be applied.

First, this approach would make cost sharing dependent on the income of the beneficiary. Higher income Medicare beneficiaries already pay higher Part D premiums, and this idea would build on this approach. This approach will be more egalitarian compared to the current low-income subsidy Medicare provides for low-income beneficiaries. The current low-income subsidy has a fixed income threshold of $\$ 17,280$ and modest assets of $\$ 13,640$ in 2016 [15]. Beneficiaries below the threshold pay very little out-of-pocket for prescription drugs, while beneficiaries just above the threshold have the standard cost-sharing mechanism. Beneficiaries just above the threshold could face huge out-of-pocket expenses relative to their income for many specialty drugs, and this affects their access to these specialty drugs.

The PDP's proportion of payment for prescription drugs over the catastrophic amount could be scaled depending on their level of high-need, high-cost beneficiaries. Currently, the cost-sharing arrangement has a fixed cost-sharing level regardless of enrollee population. It is worth noting that there is a risk corridor system across the PDP's that allocates additional funding depending on how much better or worse a PDP does relative to the average across PDPs; however, this is not specific to the level of illness of the enrolled beneficiaries or the level of catastrophic spending. Medicare and PDPs could use a sliding scale for the level of cost sharing based on a PDP's percentage of high-need, high-cost beneficiaries or the percentage of beneficiaries exceeding the catastrophic threshold. The sliding scale would minimize the level of adverse risk selection. An added benefit of the 
Table 1 Examples of cost-sharing programs sponsored by the US federal government to cultivate partnership with private entities in several major industries

\begin{tabular}{ll}
\hline Sector & Cost-sharing model \\
\hline $\begin{array}{l}\text { US Department } \\
\text { of Agricul- }\end{array}$ & Cotton Ginning Cost Share Program (2016) \\
ture (USDA) &
\end{tabular}

Farm Bill of 2014

Conservation tree planting

\author{
US Department Cost-sharing contracts [29] \\ of Defense \\ (DOD)
}

\section{Description}

The USDA provided targeted assistance to cotton growers to share in the cost of ginning. This one-time payment began in July 2016 to assist with this year's ginning season [26]. In this program, the USDA allocated $\$ 300$ million to purchase $40 \%$ of individual farmers' cotton production, at a cap of $\$ 40,000$ per farm. This cost-sharing program was based on a worldwide oversupply of cotton, whereby cotton farmers in the US were losing market share and forced to sell capital equipment to cover short-term debts. The cost-sharing program is an upfront investment from the USDA to keep farmers in the cotton market through 2016 despite competitive demand, and reduce operational costs for the 2016 farming year. No repayment in this program was necessary

The USDA allocated $\$ 24$ billion to the Crop Commodities program and $\$ 30$ billion to the Conservation Reserve Program [27]. First, the Crop Commodities program was designed to enforce that farmers of covered commodities (e.g., corn, wheat, rice, peanuts, and soybeans) receive a fair market price for their products in order to achieve expected revenue based on the size of their farm on an annual basis. Furthermore, the Conservation Reserve Program financed the conversation of highly erodible cropland to other environmentally sensitive acreage to vegetative cover (e.g., native bunchgrass and grasslands; wildlife and pollinators food and shelter plantings; windbreak and shade trees; filter and buffer strips; grassed waterways; riparian buffers). This latter program would be used to instigate a supply-side shift towards lowering expected revenues from individual farms

This USDA cost-sharing model assists private landowners to plant trees on properties for wind protection, wood products, soil and water conservation and wildlife habitats [28]. The distribution of cost sharing was that the USDA would pay landowners $50 \%$ of the cost of trees plus a $40 \%$ practice incentive payment for ensuring adherence to the purpose of planting, which could add up to $90 \%$ of the total cost-sharing incentive. This particular program provides insight into cases which the government is willing to provide as much as $90 \%$ of cost sharing with individuals, provided that the product is used properly

This DOD law defines a cost-sharing contract as a costreimbursement contract in which the contractor receives no fee and is only reimbursed for an agreed upon portion of its allowable costs. A cost-sharing contract may be used when the contractor agrees to absorb a portion of the upfront costs, with the expectation of substantial compensating benefit upon the completion of service

North Atlantic Treaty Organization (NATO)

While NATO as an entity is well known, its cost-sharing structure is less familiar, but potentially informing to the issue of prescription drug pricing and who pays. NATO's 28 members each contribute to a general fund based on a costsharing formula according to gross national income, which represents a small percentage of each member's defense budget [30]

US and Republic of South Korea Alliance
The US continues to support South Korean defense systems with a monetary investment and presence of troops and supplies inside Korea, provided Korea assumes greater responsibility for its own defense at a rate of increase of 5.3\% per year, as of 2015 [31] 
Table 1 (continued)

\begin{tabular}{|c|c|c|}
\hline Sector & Cost-sharing model & Description \\
\hline \multirow[t]{2}{*}{ Environmental } & $\begin{array}{l}\text { Byrd-Bond Amendment to the Clean Air Act of Title IV } \\
\text { (1995) }\end{array}$ & $\begin{array}{l}\text { Under this amendment, the government would establish a } \\
\text { reserve of } \mathrm{SO}_{2} \text { emissions for early investors in updates to } \\
\text { reduce long-term emissions [32]. Manufacturing and energy } \\
\text { plants investing during phase I to reduce } \mathrm{SO}_{2} \text { emissions } \\
\text { would receive credits to lower penalties for later emissions } \\
\text { in greater quantities beyond accepted margins in latter } \\
\text { phases, after } 1995\end{array}$ \\
\hline & Farm Bill: Greenhouse Gas Emissions clause & $\begin{array}{l}\text { The US government would pay } 75-90 \% \text { of the costs of vegeta- } \\
\text { tion that farmers purchase to reverse effects of greenhouse } \\
\text { gas emissions in the USA [33] }\end{array}$ \\
\hline \multirow[t]{3}{*}{ Healthcare } & Ryan White CARE Act & $\begin{array}{l}\text { The Ryan White Comprehensive AIDS Resources Emergency } \\
\text { (CARE) Act provided a safety net of coverage for high costs } \\
\text { of care in low-income, uninsured and underinsured victims } \\
\text { of AIDS and their families. The act provided funding for } \\
\text { a three-way cost-sharing program between patients, the } \\
\text { federal government (e.g., Medicaid) and private insurers. } \\
\text { Prior to the enactment, AIDS patients may have had to pay } \\
\text { completely out-of-pocket for treatment without assistance } \\
\text { from a government or private insurer }\end{array}$ \\
\hline & Center for Medicare and Medicaid Innovation (CMMI) & $\begin{array}{l}\text { CMMI has proposed several instances of equal-sided risk } \\
\text { models, in which payment hinges on improved population } \\
\text { health management [34]. Health systems that take on greater } \\
\text { upfront risk for a population are rewarded up to } 50 \% \text { relative } \\
\text { to the amount of risk that they take }\end{array}$ \\
\hline & Department of Veterans Affairs (VA) & $\begin{array}{l}\text { The VA provides low-cost drugs to veterans as a result of an } \\
\text { ability to guarantee a discounted rate of }-24 \% \text { from manu- } \\
\text { facturers, in addition to other discounts that may be applied } \\
\text { for specific drugs [35] }\end{array}$ \\
\hline Energy & Retail Ethanol Infrastructure Cost Sharing Program (2008) & $\begin{array}{l}\text { As part of the American Recovery and Reinvestment Act, } \\
\text { the US Department of Energy agreed to subsidize 15-30 } \\
\text { companies up to } \$ 3.5 \text { million to invest in the development of } \\
\text { high-grade ethanol from corn products [36] }\end{array}$ \\
\hline
\end{tabular}

sliding scale is that it could replace the need for a risk corridor across multiple PDPs and base it on the characteristics of beneficiaries the PDP enrolls.

While the application of NATO's model to specialty drug coverage has several potential benefits, it raises several concerns. Beneficiaries with an ability to pay for specialty drugs could claim that they are unfairly being targeted as a population. A sliding scale for beneficiaries would also be administratively complex to track at the patient level and cause redundancy over Part D premiums that already adjust for beneficiary income. Medicare or the PDP would need to offset the proportion of costs that a low-income beneficiary would be exempt from paying above the catastrophic amount. Finally, it is clear that social and income disparities predispose certain populations to greater prevalence of diseases that place them above the catastrophic limit more frequently. Thus, as PDPs enter highly concentrated markets of patients requiring specialty drugs, it is less likely that proportions of individuals with an ability to pay for their own specialty drugs are balanced. Nevertheless, it would allow a more continuous approach for low-income beneficiaries.

\subsection{The Byrd-Bond Amendment to the Clean Air Act}

The Byrd-Bond Amendment is an example of a "marketbased" policy approach that transcends mere modifications in cost-sharing percentages [12]. In 1990, the US government enacted a series of policies to combat the effects of pollution on the environment and public health: the Byrd-Bond Amendment to the Clean Air Act [30]. Under this amendment, the government set aside a reserve of $\mathrm{SO}_{2}$ emissions credits during phase I of the pollution reduction program. This enabled utilities that were investing heavily to reduce $\mathrm{SO}_{2}$ emissions in phase $\mathrm{I}$ to receive credits for emissions in latter phases. Effectively, the Byrd-Bond Amendment provided incentives for utilities to reduce emissions at power plants when technology made it cost-effective, thereby targeting "low-hanging" fruit, instead of attempting to reduce $\mathrm{SO}_{2}$ emissions by a fixed percentage at every plant.

Using this approach as a guide, CMS could explore several concepts. First, early adopters of an alternative cost-sharing distribution could be rewarded with greater risk-adjusted subsidies. There is precedence for Medicare 
Table 2 Analysis of proposals and select government-sponsored programs for cost sharing between Medicare and prescription drug plans (PDPs)

\begin{tabular}{|c|c|}
\hline Proposal name & Analysis of cost sharing for catastrophic prescription drug coverage \\
\hline \multicolumn{2}{|l|}{ MedPAC } \\
\hline Option $1: 80 / 15 / 5$ & $\begin{array}{l}\text { 1. Current law: Medicare pays for } 80 \% \text { of drug; PDP pays for } 15 \% \text { of drug; patient } \\
\text { pays for } 5 \% \text { of drug }\end{array}$ \\
\hline Option 2: 80/20 & $\begin{array}{l}\text { 2. Medicare pays for } 80 \% \text { of drug; PDP pays for } 20 \% \text { of drug; patient pays } 0 \% \text { above } \\
\text { catastrophic threshold }\end{array}$ \\
\hline Option 3: 20/80 & $\begin{array}{l}\text { 3. Medicare pays for } 20 \% \text { of drug; PDP pays for } 80 \% \text { of drug. Medicare also pays an } \\
\text { increased direct subsidy to the PDP }\end{array}$ \\
\hline CMMI equal-sided risk model & $\begin{array}{l}\text { 1. The proportion of PDP cost sharing above } 15-20 \% \text { is scaled based on the percentage } \\
\text { of beneficiaries reaching the catastrophic limit }\end{array}$ \\
\hline North Atlantic Treaty Organization (NATO) & $\begin{array}{l}\text { 1. The PDP's percentage of payment for prescription drugs over the catastrophic limit } \\
\text { is scaled depending on the number of high-need, high-cost beneficiaries in their } \\
\text { cohort } \\
\text { 2. The catastrophic proportion that the beneficiary is responsible is scaled based on } \\
\text { their income }\end{array}$ \\
\hline Byrd-Bond Amendment to the Clean Air Act of Title IV & $\begin{array}{l}\text { 1. PDPs that are early adopters of the } 80 / 20 \text { cost-sharing model or enroll high percent- } \\
\text { ages of beneficiaries exceeding the catastrophic threshold could receive greater risk- } \\
\text { adjusted Medicare Part D subsidies per beneficiary } \\
\text { 2. Prescription drug price purchasing: Medicare could purchase prescription drugs in } \\
\text { bulk and drive down wholesale prices } \\
\text { 3. These PDPs would get priority access to bulk quantities of drugs in wholesale for } \\
\text { PDPs }\end{array}$ \\
\hline Ryan White CARE Act & $\begin{array}{l}\text { 1. This act provides justification to shift the burden of the drug away from patients to } \\
\text { payers and the federal government } \\
\text { 2. Scaling patient copays according to income could present an overly complex amend- } \\
\text { ment; thus a flat rate of between } 0 \text { and } 5 \% \text { copay should be applied to all Medicare } \\
\text { beneficiaries } \\
\text { 3. Patients with low affordability could receive government grants to assist with copay- } \\
\text { ments for specialty drugs } \\
\text { 4. PDPs could receive grants to pay for the majority cost of prescription drug coverage } \\
\text { in high-risk markets }\end{array}$ \\
\hline Department of Veterans Affairs (VA) & 1. Medicare could adopt the VA discount rate for drugs costing more than $\$ 8000$ \\
\hline
\end{tabular}

CMMI Center for Medicare and Medicaid Innovation, MedPAC Medicare Payment Advisory Commission

rewarding early adopters. These early adopter PDPs could be eligible for having the Medicare program take more financial risk instead of the 80/20 MedPAC proposal.

In addition to the above cost-sharing principles, CMS could leverage the concept of the Byrd-Bond Amendment to directly purchase specialty drugs and distribute them to PDPs as a benefit of becoming an early adopter. This potential technically violates the statutes of the Medicare Modernization Act; however, if CMS were able to pursue this approach, it would also hold greater buying power to negotiate lower prices. This negotiation could be enhanced to the drug companies through a guaranteed purchase of set quantities of drugs upfront. Alternatively, the government could use an existing third party to evaluate thresholds at which to set prices based on a value-based framework (e.g., the incremental cost-effectiveness ratio [ICER]), [16] or establish its own value-based purchasing division, just as the UK has invested in the National Institute for Health and Care Excellence (NICE) to assess the cost-effectiveness of drugs at manufacturer-proposed prices based on societal willingness-to-pay thresholds of value.

To understand the impact of the federal government negotiating to achieve lower drug prices, one could look to the VA for examples of bulk purchasing and rate setting. Research has attributed the VA's ability to negotiate significantly lower drug prices to its restrictive formularies [17]. It has been suggested that VA's drug prices are approximately $60 \%$ of those paid by Medicare, although with rebates and other discounts it is difficult to obtain a precise amount [15]. Using the Byrd-Bond Amendment model, Medicare could negotiate only for the high-priced specialty drugs that individually place a patient above the catastrophic limit. However, the Congressional Budget Office (CBO) believes that Medicare would not be able to negotiate lower prices without the use of a restrictive formulary, [18] and in this case, the restrictive formulary would only apply to $1 \%$ of prescription drugs (i.e., drugs that cost more than $\$ 8000$ per annual treatment regimen). Table 3 highlights 20 drugs that are likely to fit the Medicare definition of high priced [19]. 
Table 3 Twenty high-priced specialty drugs covered by Medicare Part D with fewer than 200,000 beneficiaries and less than 1 million claims filled in 2013

\begin{tabular}{|c|c|c|c|c|c|}
\hline Generic name & Therapeutic class & Beneficiaries $(N)$ & Claims $(N)$ & $\begin{array}{l}\text { Cost to Part D (in } \\
\text { millions of US\$) }\end{array}$ & $\begin{array}{l}\text { Overall rank on Part } \\
\text { D reimbursement list }\end{array}$ \\
\hline 1. Lenalidomide & Cancer & 24,637 & 153,782 & 1350 & 10 \\
\hline 2. Glatiramer acetate & Unclassified & 27,424 & 224,167 & 1120 & 13 \\
\hline 3. Etanercept & Arthritis & 50,570 & 354,298 & 980 & 15 \\
\hline 4. Adalimumab & Arthritis & 46,448 & 325,242 & 960 & 16 \\
\hline 5. Imatinib & Cancer & 13,684 & 110,658 & 780 & 21 \\
\hline 6. Sevelamer carbonate & Mineral supplement & 184,164 & 939,717 & 730 & 22 \\
\hline 7. Emtricitabine/tenofovir & Anti-infective & 57,263 & 488,245 & 620 & 29 \\
\hline 8. Cinacalcet hydrochloride & Unclassified & 117,921 & 117,921 & 610 & 31 \\
\hline 9. Quetiapine fumarate & Psychotherapeutic & 143,622 & 999,405 & 540 & 35 \\
\hline 10. Efavirenz/emtricitabine/tenofovir & Anti-infective & 29,585 & 264,284 & 530 & 37 \\
\hline 11. Abiraterone acetate & Cancer & 14,191 & 71,423 & 470 & 43 \\
\hline 12. Bosentan & Unclassified & 7100 & 64,824 & 450 & 48 \\
\hline 13. Paliperidone palmitate & Psychotherapeutic & 38,061 & 303,094 & 420 & 52 \\
\hline 14. Erlotinib hydrochloride & Cancer & 14,237 & 71,058 & 400 & 54 \\
\hline 15. Raltegravir potassium & Anti-infective & 39,132 & 338,249 & 380 & 57 \\
\hline 16. Interferon beta-1A & Unclassified & 9983 & 80,328 & 370 & 60 \\
\hline 17. Ambrisentan & Unclassified & 6040 & 49,128 & 330 & 66 \\
\hline 18. Darunavir ethanolate & Anti-infective & 34,353 & 289,830 & 330 & 67 \\
\hline 19. Interferon beta-1A albumin & N/A & 7894 & 66,819 & 300 & 81 \\
\hline 20. Everolimus & Cancer & 7568 & 32,123 & 270 & 88 \\
\hline
\end{tabular}

N/A Not Applicable

\subsection{The Center for Medicare and Medicaid Innovation (CMMI) Equal-Sided Risk Model}

The CMMI has explored a number of equal-sided risk models with providers since its inception in 2010. By definition, these models reward insurers with revenue bonuses proportional to the amount of upfront risk they would have taken [32]. With respect to PDPs, they have traditionally been responsible for $15 \%$ of the risk above the catastrophic level. For instance, MedPAC's recommendation of shifting PDPs from 15 to $80 \%$ cost sharing could be costly to PDPs in a high-risk market concentrated with patients taking specialty drugs. To offset this risk, the PDP's cost share could be scaled according to the risk in their market relative to Part D. For example, PDPs would cover $20 \%$ of the cost in a high-risk market relative to Medicare's $80 \%$, mid-level risk markets could be split 40/60, and in low-risk markets, the PDP could take on $60-80 \%$ of the risk. Alternatively, it could be based on the number of high-need beneficiaries in the PDP or the number of beneficiaries reaching the catastrophic phase.

An equal-sided risk model for catastrophic coverage on a sliding scale as a function of market risk could benefit the Part D system for several reasons. It still empowers PDPs to be the majority stakeholder in purchasing drugs for Part $\mathrm{D}$ in many markets, thereby potentially leveraging a PDP's ability to negotiate prices based on a formulary structure. Furthermore, it ensures that PDPs will remain in high-risk markets.

\subsection{The Ryan White CARE Act of 1990}

At the time that HIV/AIDS became prevalent in the USA during the late 1980s and early 1990s, few insurance companies covered the full cost of expensive, newly innovated medications. This reality combined with the pre-Affordable Care Act era where many people were uninsured or underinsured left many individuals without protection against the cost burden to treat HIV/AIDS. The Ryan White CARE Act allocated federal dollars to create a three-way cost-sharing program between the federal government, private payers, and patients so that patients would not have to cover the full cost of care [20]. The purpose of the act was to reduce or eliminate the cost burden to the patient, since low-income individuals accounted for the majority of patients with HIV/ AIDS in that era.

The Ryan White CARE Act consisted of several parts that worked together to make HIV/AIDS treatments accessible [21]. The act provided grant funding to eligible metropolitan 
areas with high concentrations of patients in need; funding to states to improve the availability of HIV healthcare; grant funding to community-based organizations to deliver quality HIV care; grant funding directly to women and their children infected with HIV; and support for research into HIV/AIDS treatments.

The Ryan White CARE Act provides a healthcare framework for reducing a patient's out-of-pocket burden in cases where the drugs to treat patient's condition are unaffordable. It would suggest greater support to low-income beneficiaries. However, the Ryan White CARE Act does suggest that beneficiaries should share a reasonable proportion of the cost. Those patients who cannot afford specialty drugs could receive grants to directly participate in purchasing drugs at set copays. In addition, the structure of this act could offset PDP concerns about high-risk markets if the government provided grants to PDPs to offset the $80 \%$ majority share of costs.

\section{Discussion}

The prices of specialty drugs have risen substantially in the past several years while the mean household income of Medicare beneficiaries in the USA has remained relatively stagnant. As a result, Medicare beneficiaries have experienced increasing pressure regarding paying for specialty drugs. Furthermore, these changes have increased overall spending for Medicare Part D. This program, which is now 15 years old, could use new tools to manage Medicare spending and realign incentives of public-private partnerships so that the PDPs that work with Part D to cover patient drugs help control spending and the prices of drugs.

There are several opportunities to make adjustment to current responsibilities. MedPAC offers an alternative to the current $80 / 15 / 5$ model by shifting the responsibility and having Medicare and PDPs cover 20 and $80 \%$ of the costs, respectively, as well as eliminating the cost sharing for the beneficiary. This model assumes that Medicare's riskadjusted subsidy per beneficiary to the PDP would increase to offset costs and create a net neutral cost solution for the PDP. However, there is a concern that could lead to some PDPs exiting markets with high concentrations of high-need, high-cost beneficiaries if they are concerned that the subsidy will not be sufficient relative to the cost of covering patients who reach the catastrophic threshold.

The NATO model offers two insights into cost sharing. Just as NATO members pay according to affordability, the proportion of drug costs above a catastrophic limit that beneficiaries pay could be scaled to their income. One could argue that the amount of out-of-pocket expenses for which a patient should be responsible should be scaled based on their income. However, Medicare already sets premiums in
Part B based on income, and this could be adopted in Part D catastrophic spending. Alternatively, Medicare's proportion of cost sharing with the PDP could be scaled depending on the complexity of the panel that the PDP covers, so that if a PDP is generally paying for a large proportion of patients above the catastrophic limit, then Medicare will pay for a greater percentage of the cost of the drugs.

The Byrd-Bond Amendment to the Clean Air Act provides an example of rewarding entities for investing in highly valued commodities. In this case, the government would encourage PDPs to enter high-risk markets. Medicare could purchase specialty drugs in bulk and distribute these drugs to PDPs. This approach is not unlike the VA's current system through the purchase of large quantities of drugs for Veterans. A hybrid model of the VA and Byrd-Bond Amendment could grant Medicare negotiating power to offer specialty drugs at more reasonable prices.

The Ryan White CARE Act would justify some fixed margin of cost sharing for the beneficiary between the $0 \%$ recommendation by MedPAC and Medicare's current model of $5 \%$. The Ryan White CARE Act actually favors each party taking some responsibility, including the patient, regardless of ability to pay.

An equal-sided payment model, such as several CMMI demonstrations have adopted, could empower PDPs to negotiate drug prices on behalf of Medicare without taking the same level of long-term financial risk as a simple 20/80 model plus a subsidy. This model would ensure that most patients at the catastrophic level maintain access to PDPs. The risk would be based on the percentage of high-need beneficiaries in the PDP or the percentage of beneficiaries in the catastrophic phase.

There are a number of questions regarding scope and mechanism that would need to be addressed before Medicare could undertake negotiation if given the authority by the US Congress to do so. For example, Medicare would have to determine which drugs would be subject to negotiations, what would be negotiated (i.e., price or formulary placement), and how to implement negotiated prices in Part D plans [22]. A pricing model to guide decisions would need to be defined, including how various types of evidence and other considerations would inform conclusions on drug value and price. Factors such as evidence of clinical benefit and the impact of drug pricing on future research and development would likely play a role [23]. A recently proposed payment framework for negotiation focuses on drugs that are "high cost (e.g., \$1000 per month), incur high levels of Part D program spending (more than $\$ 500$ million), and have few close substitutes" [23]. The goal of this framework is to develop a negotiated payment system that would simultaneously enable profits for manufacturers and improve health outcomes for patients. This proposal also uses net 
health benefit measured in units of quality-adjusted life years (QALYs) as a key metric to assess the "value" of drugs.

Ultimately, these different models provide alternatives for policy makers to consider. There are clear unintended consequences of the MedPAC approach where the financial responsibility shifts largely away from Medicare. One concern is that PDPs may exit high-risk markets or develop ways to discourage enrollment of high-risk individuals. There is also little government precedent to place the majority risk on a private entity that goes into agreement with the federal government. Without knowledge of how effectively this model has worked in other markets before, it would be difficult to comment on the benefit to patients.

Each of these models provides different guidance concerning the appropriate level of beneficiary cost sharing. Given that the RAND Health Insurance Experiment is over 30 years old, and costly specialty drugs did not exist in the same magnitude as they do today, it could be time for a second iteration of this randomized clinical trial to better understand what proportion of coverage most Part $\mathrm{D}$ beneficiaries can afford and still utilize necessary care responsibly [24]. It is difficult to assess the impact using observational data.

Applying an approach to value-based purchasing such as cost-effectiveness analysis could also help determine a framework for assessing the prices of specialty drugs. However, several unintended consequences of this approach need to be considered. The willingness-to-pay thresholds of specialty drugs would need to be set in a manner that stabilizes the prices of specialty drugs without allowing other classes of drugs in competitively priced markets to adopt unnecessary price hikes. Value-based purchasing also needs to provide drug manufacturers with the incentive to continue innovating as well as to continue to market their products to consumers However, we see that markets with value-based purchasing have been impacted by a slowing of innovation as well as reduced availability of certain drugs [25].

One composite approach is to tailor the beneficiaries cost sharing based on income. Medicare could gradually increase the PDP's share 5-10\% per year and observe how volatile markets become. Medicare could also allow for cost sharing between Medicare and the PDPs based on the percentage of high-need beneficiaries enrolled in the plan or the percentage of beneficiaries entering the catastrophic phase. Where PDPs begin to pull out of the high-risk markets, Medicare can set upper thresholds on cost sharing as appropriate

In conclusion, revisions of the catastrophic cost-sharing provisions could incorporate elements of several costsharing policies that have been used by the federal government or other governments, including eliminating beneficiary responsibility, incentivizing greater risk to PDPs, and controlling the prices of specialty drugs. Still, no policy offers direct precedent for how a US federal entity such as
Medicare Part D should properly interact with private entities to improve the outcomes of patients and determine the appropriate price. The greatest concern created by the existing system is that beneficiaries will continue to limit their own access to drugs that they cannot afford, which provides the greatest justification for government to act differently in order to improve patient access to life-saving therapies.

Acknowledgements The Authors wish to thank Rep. Henry Waxman, Dr. Joseph Antos, William Corr, Saul Kilstein, and Sean Cavanaugh for their valuable input on policy concepts outlined in this manuscript.

Author Contributions WP and JB conducted the systematic review of cost-sharing policies. GA provided an analysis of the MedPAC proposal. All three authors contributed equally to writing the manuscript.

\section{Compliance with Ethical Standards}

The efforts of William Padula, Jeromie Ballreich, and Gerard Anderson were supported by awards from the Commonwealth Fund and the Arnold Foundation to Johns Hopkins University.

Funding This investigation was supported by an unrestricted Grant from the Commonwealth Fund and the Arnold Foundation to Johns Hopkins University.

Conflict of interest William Padula, Jeromie Ballreich and Gerard Anderson have no other conflicts of interest to declare.

Open Access This article is distributed under the terms of the Creative Commons Attribution-NonCommercial 4.0 International License (http://creativecommons.org/licenses/by-nc/4.0/), which permits any noncommercial use, distribution, and reproduction in any medium, provided you give appropriate credit to the original author(s) and the source, provide a link to the Creative Commons license, and indicate if changes were made.

\section{References}

1. Medicare Prescription Drug, Improvement and Modernization Act, Pub Law No. 108-173. 2003.

2. The Medicare Part D Prescription Drug Benefit. Fact sheet. The Kaiser Family Foundation. 2017. https://www.kff.org/medicare/ fact-sheet/the-medicare-prescription-drug-benefit-fact-sheet/. Accessed 25 Apr 2018. (Published October 2, 2017).

3. The Medicare Part D Prescription Drug Benefit. Fact sheet. The Kaiser Family Foundation. 2016. http://kff.org/medicare/factsheet/the-medicare-prescription-drug-benefit-fact-sheet. Accessed 17 Oct 2017. (Published September 26, 2016).

4. Partnership for Solutions. Chronic conditions: making the case for ongoing care. Princeton, NJ: The Robert Wood Johnson Foundation. 2002. http://www.partnershipforsolutions.org/DMS/files /2002/. Accessed 17 Oct 2017.

5. Cavanaugh S, Lazio JW. Announcement of calendar year (CY) 2016 Medicare Advantage Capitation Rates and Medicare Advantage and Part D payment policies and final call letter. Baltimore, MD: Centers for Medicare and Medicaid Services (CMS). 2015. http://www.cms.gov/medicare/health-plans/medicareadvtgspecrat 
estats/downloads/announcement2016.pdf. Accessed 17 Oct 2017. (Published April 6, 2015).

6. Dusetzina SB. Share of specialty drugs in commercial plans nearly quadrupled, 2003-2014. Health Aff (Millwood). 2016;35:1241-6.

7. Trish E, Xu J, Joyce G. Medicare beneficiaries face growing outof-pocket burden for specialty drugs while in catastrophic coverage phase. Health Aff (Millwood). 2016;35:1564-71.

8. Lew JJ, Perez TE, Burwell SM, Colvin CW, Slavitt AM. The Boards of Trustees, Federal Hospital Insurance and Federal Supplementary Medical Insurance Trust Funds (2016). The 2016 annual report of the Boards of Trustees of the Federal Hospital Insurance and Federal Supplementary Medical Insurance Trust Funds. Baltimore, MD: Centers for Medicare and Medicaid Services (CMS). 2016. https://www.cms.gov/Research-Statistics -Data-and-Systems/Statistics-Trends-and-Reports/ReportsTru stFunds/Downloads/TR2016.pdf. Accessed 17 Oct 2017.

9. Ornstein C. Medicare spending for hepatitis $C$ cures surges. Washington, DC: Health \& Science; 2015 (The Washington Post; October 16, 2015).

10. Lee C. Although a small share of Medicare Part D enrollees take specialty drugs, a new analysis finds those who do can face thousands of dollars in out-of-pocket drug costs despite plan limits on catastrophic expenses. Newsroom. Menlo Park, CA: The Henry J. Kaiser Family Foundation; December 2, 2015. 2015. http://kff. org/medicare/press-release/although-a-small-share-of-medicarepart-d-enrollees-take-specialty-drugs-a-new-analysis-finds-those -who-do-can-face-thousands-of-dollars-in-out-of-pocket-drugcosts-despite-plan-limits-on-catastrophi/. Accessed 10 Apr 2017.

11. Grassley C. Grassley, Brown urge CMS to maintain policy requiring Medicare Part D plans to carry medicines in six categories. News Releases; July 5, 2016. 2016. http://www.grassley.senat e.gov/news/news-releases/grassley-brown-urge-cms-maintainpolicy-requiring-medicare-part-d-plans-carry. Accessed $10 \mathrm{Oct}$ 2017.

12. The Medicare Payment Advisory Council (MedPAC). Chapter 6: Improving Medicare Part D. In: Report to Congress: Medicare and the Health Care Delivery System. 2016. http://www.medpac.gov/ docs/default-source/reports/chapter-6-improving-medicare-part-djune-2016-report-.pdf. Accessed 10 Apr 2017.

13. The Medicare Payment Advisory Council (MedPAC). Chapter 14: The Medicare Prescription Drug Program (Part D): status report. In: Report to Congress: Medicare Payment Policy. 2018. http:// www.medpac.gov/docs/default-source/reports/mar18_medpa c_entirereport_sec.pdf. Accessed 25 Apr 2018.

14. Popp D. Pollution control innovations and the Clean Air Act of 1990. J Policy Anal Manage. 2003;22:641-60.

15. The Medicare Part D Prescription Drug Benefit. Medicare. Menlo Park, CA: The Kaiser Family Foundation; September 26, 2016. $\mathrm{http} / / / \mathrm{kff}$. org/medicare/fact-sheet/the-medicare-prescription-drugbenefit-fact-sheet/. Accessed 10 Oct 2017.

16. Cohen JT, Anderson JE, Neumann PJ. Three sets of case studies suggest logic and consistency challenges with value frameworks. Value Health. 2017;20:193-9.

17. Frakt AB, Pizer SD, Feldman R. Should Medicare adopt the Veterans health administration formulary? Health Econ. 2012;21:485-95.

18. A detailed description of CBO's cost estimate for the Medicare prescription drug benefit. Washington, D.C.: The Congressional Budget Office. 2004. http://www.cbo.gov/sites/default/files/108th -congress-2003-2004/reports/07-21-medicare.pdf. Accessed 10 Apr 2017.
19. Burch M, Thompson HA. Top prescription drugs in Medicare Part D. New York: The Wall Street Journal; May 5, 2015. 2015. http:// graphics.wsj.com/medicare-prescription-drugs. Accessed 17 Oct 2017.

20. Ryan White CARE Act. Pub Law No. 101-381, 104 Stat. 576. 1990.

21. About the Ryan White HIV/AIDS Program. Washington, DC: Health Resource \& Service Administration (HRSA). 2016. https ://hab.hrsa.gov/about-ryan-white-hivaids-program/about-ryanwhite-hivaids-program. Accessed 10 Apr 2017.

22. Shih YC, Chien CR, Moguel R, Hernandez M, Hajek RA, Jones LA. Cost-effectiveness analysis of a capitated patient navigation program for Medicare beneficiaries with lung cancer. Health Serv Res. 2016;51(2):746-67.

23. Frank R, Zeckhauser R. A framework for negotiation in Medicare Part D. Hutchins Center Working Paper 28. Washington, DC: The Hutchins Center on Fiscal and Monetary Policy at Brookings. 2017.

24. Manning WG, Newhouse JP, Duan N, Keeler EB, Liebowitz A. Health insurance and the demand for medical care: evidence from a randomized experiment. Am Econ Rev. 1987;77:251-77.

25. Goldman DP, Jena AB, Philipson T, Sun E. Drug licenses: a new model for pharmaceutical pricing. Health Aff (Millwood). 2008;27(1):122-9.

26. Politsch K. USDA provides targeted assistance to cotton producers to share in the cost of ginning. Press Release No. 0140-16. Washington, DC: US Department of Agriculture. 2016. http://www. usda.gov/wps/portal/usda/usdahome? contentid=2016/06/0140. $\mathrm{xml} \&$ contentidonly=true. Accessed 17 Oct 2017.

27. The Agriculture Act of 2014. Pub Law No. 113-79. 2014.

28. Cost sharing programs for conservation tree planting in Nebraska. Fact sheet. Washington, D.C.: US Department of Agriculture. 2013. http://www.nrcs.usda.gov/Internet/FSE_DOCUMENTS/ nrcs142p2_029330.pdf. Accessed 23 July 2018.

29. 48 CFR 16.303. 2010.

30. North American Treaty Organization (NATO). Funding NATO. http://www.nato.int/cps/en/natohq/topics_67655.htm. Accessed 17 Oct 2017.

31. Whyte L. Evolution of the U.S.-ROK Alliance: who should pay for what? Tokyo: The Diplomat; August 9, 2015. 2015. http://thedi plomat.com/2015/08/evolution-of-the-u-s-rok-alliance-who-shoul d-pay-for-what/. Accessed 17 Oct 2017.

32. Trumka RL. Deferred cost-sharing through Title IV of the 1990 Clean Air Act Amendments. Villanova Environ Law Commons. 1992;2:247-81.

33. Parton WJ, Del Grosso SJ, Marx E, Swan AL. Perspective: agriculture's role in cutting greenhouse gas emissions. Issues Sci Technol. 2011;27(4):29-32.

34. Spector JM, Studebaker B, Menges EJ. Provider payment arrangements, provider risk, and their relationship with the cost of healthcare. Schaumburg: Society of Actuaries; 2015.

35. Blumenthal D, Squires D. Drug price control: how some government programs do it. To the Point. Washington, DC: The Commonwealth Fund; May 10, 2016. 2016.

36. DOE announces Recovery Act funding of up to $\$ 5.5$ Million for ethanol blends infrastructure and outreach (2009). Washington, DC: U.S. Department of Energy (DOE); August 5, 2009. 2009. http://energy.gov/eere/bioenergy/american-recovery-and-reinv estment-act. Accessed 17 Oct 2017. 